\title{
High Temperature Corrosion Failure of a Secondary Superheater Tube in a Thermal Power Plant Boiler
}

\author{
D. Ghosh", H. Roy, S. Ray and A. K. Shukla \\ NDT and Metallurgy Division \\ Central Mechanical Engineering Research Institute, Durgapur-713209, India
}

(Received April 23, 2009; final form April 30, 2009)

\begin{abstract}
Failures of boiler tubes are a foremost cause of the unscheduled outages of the thermal power plant boiler. The failure of the boiler tubes occurs due to various reasons like creep, fatigue, corrosion and erosion. This paper highlights a case study of typical premature failure of a platen superheater tube of thermal power plant boiler. Visual examination, dimensional measurement, chemical analysis, oxide scale thickness measurement, microstructural examination, Energy Dispersive spectroscopy (EDS) were carried to ascertain the probable cause/causes of failure of inner leg of platen super heater tube. From the investigation, it was finally concluded that the presence of potassium (K) and sulphur $(\mathrm{S})$ in the deposited ash may be responsible for formation of low melting compound alkali- iron trisulfate. The combination of localized high tube metal temperature and wall thinning due to high temperature fireside corrosion led to the premature tube failure.
\end{abstract}

Keywords: Boiler; High temperature corrosion; Failure; Platen Superheater.

\footnotetext{
" Corresponding Author:

Debashis Ghosh

NDT \& Metallurgy Division,

Central Mechanical Engineering Research Institute, Durgapur-713209, India

Tel.: +91-343-6452083/6510233; Fax: +91-343-2546745/2548204

E-mail address: dghosh@cmeri.res.in, dbs1012000@yahoo.co.in
}

\section{INTRODUCTION}

Low alloy ferritic steels viz. $2.25 \mathrm{Cr}-1 \mathrm{Mo}$ and $\mathrm{I} \mathrm{Cr}$ 0.5 Mo are used extensively for the construction of water wall, economizer, superheater and reheater tube panels/ banks of the boiler $/ 1,2 /$. Platen superheater tube banks are located in radiant zone in the furnace and very often exposed to high temperature. Different high temperature damage mechanisms like creep, fireside corrosion are becoming operative in superheater tube banks during operation and causes material degradation which finally leads to premature failure $/ 3 /$. Fireside corrosion of the liquid molten ash deposits at the high temperature can cause wall thinning and contributing to stress rupture failure. Fire side corrosion problem often exists in the superheater tube above temperature $853 \mathrm{~K}$ 14/. In pulverized coal fired boilers corrosive ash will form the deposit over outer surface of the tubes. The presence of both $\mathrm{Na}$ and $\mathrm{K}$ and $\mathrm{Sin}$ the ash in presence oxidizing atmosphere will form low melting eutectic alkali tri iron sulfate $(\mathrm{Na}, \mathrm{K})_{3} \mathrm{Fe}\left(\mathrm{SO}_{4}\right)$. The alkali iron trisulphate forms by reaction of alkali sulphates with iron oxide in the presence of $\mathrm{SO}_{3}$ and have a maximum melting temperature (1:1 mixture of sodium and potassium salts) of $825 \mathrm{~K}$, whereas melting points of simple sulphates are $1157 \mathrm{~K}$ for $\mathrm{Na}_{2} \mathrm{SO}_{4}$ and $1342 \mathrm{~K}$ for 
$\mathrm{K}_{2} \mathrm{SO}_{4}$. /5-6/.This paper highlights a case study on probable cause in a typical premature platen superheater tube failure in a thermal power plant boiler of $210 \mathrm{MW}$ capacity. The as received failed tube is shown in Fig 1. The material specification, design and operating parameters of the tube as obtained from the plant are given as follows.

1. Material specification of the tube: SA-213 T22 (2.25 Cr-1 Mo steel)

2. Working Temperature and pressure of the tube: 798 $\mathrm{K} \& 90 \times 10^{4} \mathrm{~kg} / \mathrm{m}^{2}$.

3. Location of failure: Bottom bend of platen superheater tube

4. Effective running hours: $1,26,543$ hours

5. Nominal dimension of the tube: $44.5 \mathrm{~mm}$ (Outside diameter) X $4.5 \mathrm{~mm}$ Thk.

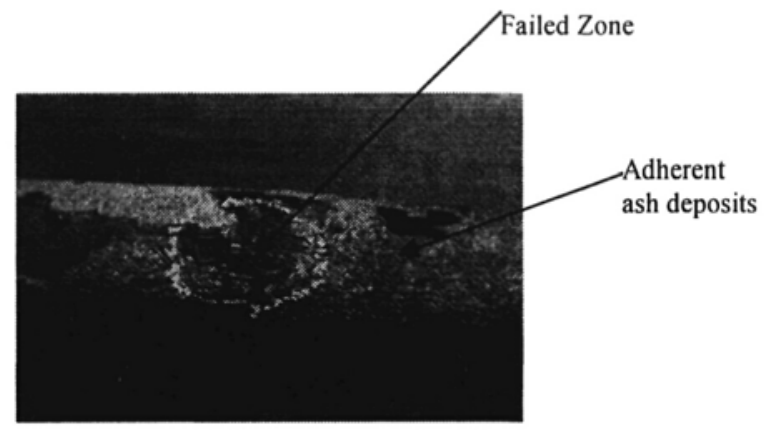

Fig. 1: As received failed tube

\section{EXPERIMENTAL PROCEDURE}

The following tests were carried out to identify the probable cause/causes of failure.

Visual examination

Dimensional measurement

Chemical analysis

Oxide scale thickness measurement

Sulfur print

Metallographic examination

EDS X-ray microanalysis

\subsection{Visual examination and dimensional measurement}

The visual inspection revealed a small puncture along the fireside of the failure. Longitudinal scale cracking and thick adherent ash deposit was found around the failure zone (Fig 2). A thick deposit on the fireside was observed in the outer surface of the tube slightly away from the puncture zone (Fig 3). The outer diameter (OD) and wall thickness were measured by using Vernier caliper and ultrasonic wall thickness gauge (Type: DM-3, Krautkramer, Germany). The minimum thickness found near the region of failure is $1.6 \mathrm{~mm}$.whereas outside diameter is $50.0 \mathrm{~mm}$. The dimensional measurement revealed significant reduction in wall thickness and increase in diameter in the form of bulging around the failure zone.

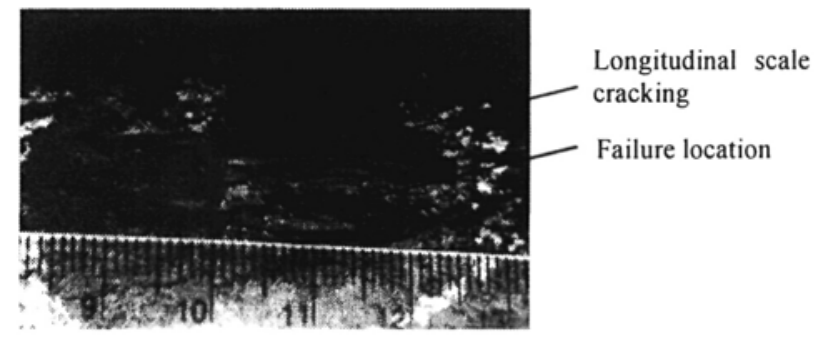

Fig. 2: Close view of the failure showing longitudinal scale cracking

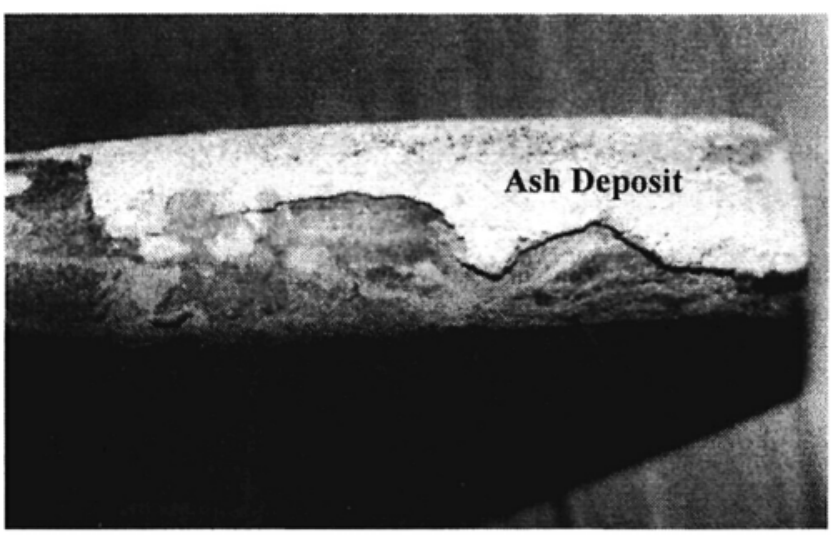

Fig. 3: Thick ash deposits on outer surface of the tube (Adjacent to the failure zone)

\subsection{Chemical analysis}

The adherent ash deposits are removed from the failed tube and chemically analyzed. The results are given in Table 1 (a); the chemical composition confirms the specification of SA-213 T22 (2.25 Cr-1 Mo steel). 
The Fireside ash deposit is removed from failed tubes in the form of powder and subjected to chemical composition. The results of ash analysis are given in Table 1 (b).

Table 1(a)

Chemical composition of the tube material (mass \%)

\begin{tabular}{|l|l|l|l|l|l|l|l|}
\hline Location & $\mathrm{C}$ & $\mathrm{S}$ & $\mathrm{P}$ & $\mathrm{Si}$ & $\mathrm{Mn}$ & $\mathrm{Cr}$ & Mo \\
\hline Tube material & 0.15 & 0.008 & 0.029 & 0.22 & 0.44 & 2.27 & 1.43 \\
\hline
\end{tabular}

Table 1(b)

Chemical composition of the deposited ash (mass \%)

\begin{tabular}{|l|l|l|l|l|l|l|l|l|l|l|l|l|}
\hline Location & $\mathrm{Si}$ & $\mathrm{Cr}$ & $\mathrm{Mo}$ & $\mathrm{Al}$ & $\mathrm{Mg}$ & $\mathrm{P}$ & $\mathrm{S}$ & $\mathrm{K}$ & $\mathrm{Ca}$ & $\mathrm{Ti}$ & $\mathrm{Fe}$ & $\mathrm{Zn}$ \\
\hline Ash & 20.54 & -- & - & 2.89 & 1.57 & 2.33 & 1.58 & 31.77 & 1.97 & 3.13 & 31.99 & 2.31 \\
\hline
\end{tabular}

\subsection{Oxide scale thickness measurement}

Small specimens were cut from the failure zone of the failed tube, polished up to 1000 grade emery paper followed by cloth polishing and then viewed under optical microscope in unetched conditions (Fig 4). The average oxide scale thickness at inner diameter (I.D) side was found to be $0.18 \mathrm{~mm}$. The average tube metal temperature calculated from the standard rate laws for oxide scale growth kinetics as suggested by Paterson et al. / $7 /$ is $858 \mathrm{~K}$.

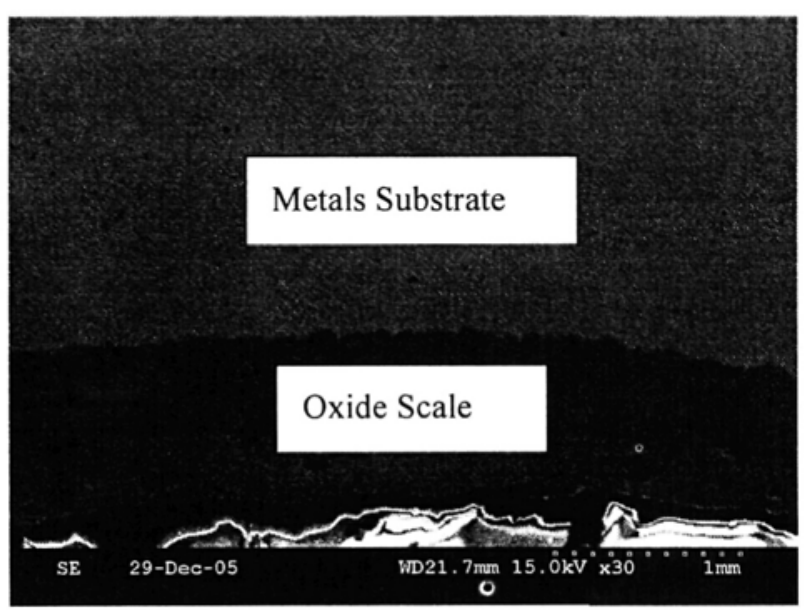

Fig. 4: Oxide scale at side of the tube near failure zone

\subsection{Sulphur print}

Sulphur print of the failed tube samples from the adjacent area of the failure is done by using a piece of photographic paper dipped in $2 \%$ sulphuric acid solution and excess acid is wiped off. The prepared tube samples were pressed on the damp photographic paper for 3-4 minutes and then removed. The sulphur print showed presence of sulfur on the outer surface of the tube around the failure zone (Fig. 5).

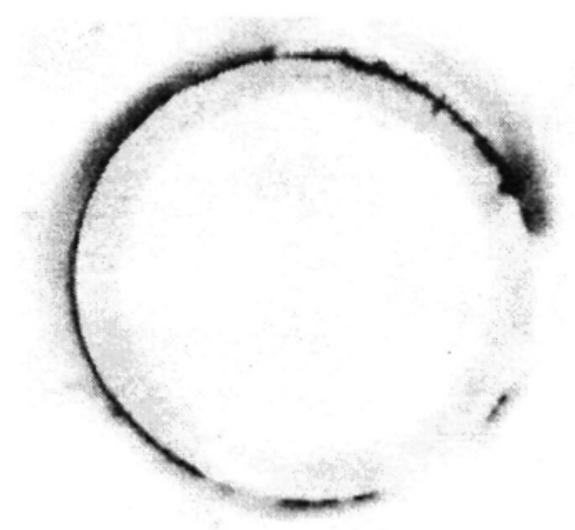

Fig 5: Sulfur print shows the presence of sulfur on the outer surface of the tube (indicated by brownish line) 


\subsection{Metallographic examination}

The specimen from the failed area is selected for metallographic examination. The microstructural features of the failure zone at unetched condition confirmed the presence of grain boundary sulfide attack near the failure zone (Fig. 6). The microstructural examination at etched condition also confirmed, partially spheroidised carbides and isolated creep cavities (Fig. 7).

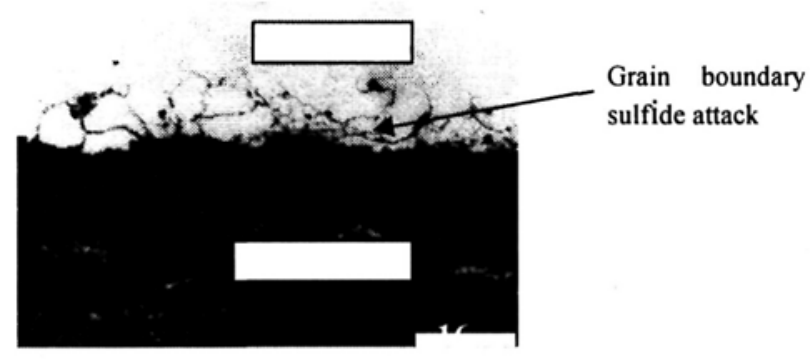

Fig. 6: Grain boundary sulfide attack near failure zone

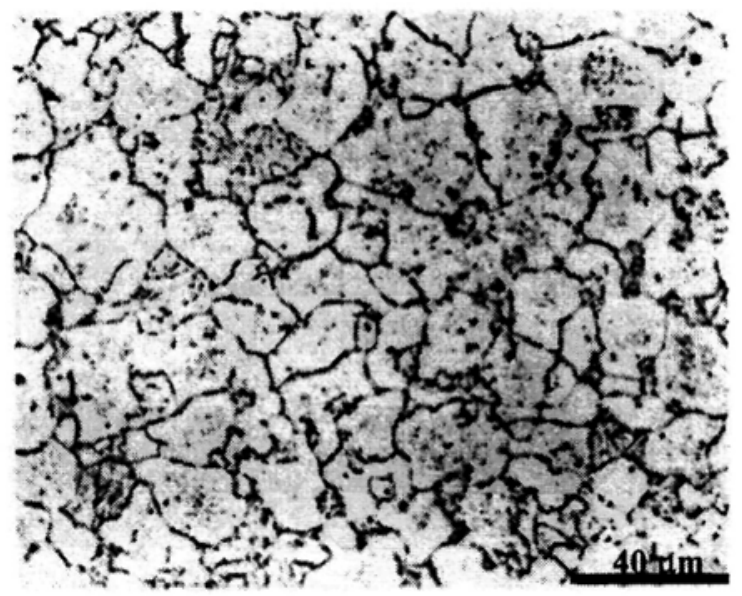

Fig. 7: Microstructure revealed ferrite, partially spheroidised carbides and isolated creep cavities at the grain boundaries.

\subsection{EDX microanalysis}

The EDS X-ray microanalysis was carried out on interface between tube OD using EDS (make: Thermonoran USA) attached with scanning electron microscope (HITACHI S-3000N). The analysis was carried out and is shown in (Fig. 8 and Table 2).

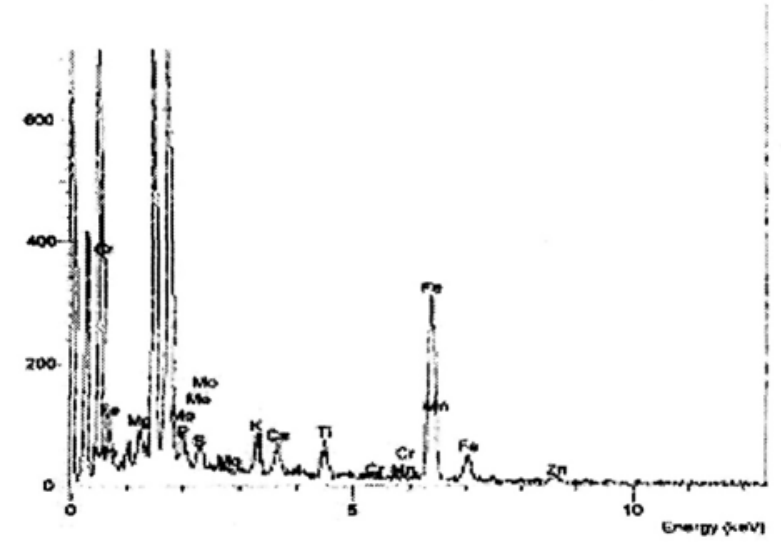

Fig. 8: EDS microanalysis in Interface between tube OD and ash deposits

Table 2

Chemical composition in mass percent

\begin{tabular}{|c|c|}
\hline Element & Mass percent \\
\hline $\mathrm{Mg}$ & 1.57 \\
\hline $\mathrm{Al}$ & 20.54 \\
\hline $\mathrm{Si}$ & 31.77 \\
\hline $\mathrm{P}$ & 2.33 \\
\hline $\mathrm{S}$ & 1.58 \\
\hline $\mathrm{K}$ & 2.89 \\
\hline $\mathrm{Ca}$ & 1.97 \\
\hline $\mathrm{Ti}$ & 3.13 \\
\hline $\mathrm{Fe}$ & 31.91 \\
\hline $\mathrm{Zn}$ & 2.31 \\
\hline
\end{tabular}

\section{RESULTS AND DISCUSSIONS}

The failure is associated with small narrow punctures with longitudinal scale cracking. Thick adherent ash deposits are also covered on the outer surface in and around the failure zone (Fig. 2 and Fig. 3). Considerable reduction of wall thickness combined with bulging of the tube around the failure zone is also observed. The tube metal temperature estimated from the ID side oxide scale thickness (Fig. 4) as suggested by Paterson et al. $/ 7 /$ is $858 \mathrm{~K}$ near the failure zone. The sulphur print (Fig. 5) of the samples indicated the presence of sulfur in between base metal and outside 
adherent ash deposit. Microstructural examination at unetched condition revealed grain boundary sulfide attack initiated from outer ash deposits surfaces to the inner side (Fig. 6). The microstructure of the failure zone also revealed isolated creep cavities along with ferrite and spheroidised carbides which also support high temperature exposure in the failure zone (Fig. 7). The chemical composition of the ash showed the appreciable amount of potassium (K) and sulfur(S) [Table 1(b)]. The estimated tube metal temperature near the failure zone is above the temperature of low melting eutectic of potassium tri iron sulfate, which sticks on outer surface of the tube and accelerates the metal wastage due to fire side ash corrosion. The results of EDS X-ray microanalysis on the interface of the tube metal and ash deposit confirm the presence of potassium (K) and sulfur(S) (Fig. 8 and Table 2).

\section{CONCLUSIONS}

The presence of potassium (K) and sulphur (S) in the deposited ash may be responsible for formation of low melting eutectic alkali-iron trisulfate on the outer surface of the tube. The estimated tube metal temperature at the failure zone is very favorable for the formation of low melting alkali tri iron sulfate and further causes fireside corrosion on the outer surface of the tube. The drastic wall thinning from the outer surface due to high temperature corrosion caused the premature failure of the tube.

\section{ACKNOWLEDGEMENT}

The authors would like to thank the director, Central Mechanical Engineering Research Institute, Durgapur, India for his kind permission to publish this paper.

\section{REFERENCES}

1. A.K. Khare, Proceedings of the ASM International Conference, Warrandale PA, Cleveland, OH: ASM (1981).

2. S.F. Pugh and E.A. Little, Proceedings of BNES international conference on ferritic steels for fast reactor steam generators, London: BWES, (1978).

3. R. Viswanathan, Damage mechanism and Life assessment of high temperature components, ASM International Metals Park, Ohio, USA (1989 ). p. 207

4. W. Nelson and C.Cain, Jr., Trans. ASME, $J$ of Engineering for Power, series A, 82, 194 (1960).

5. G. A. Lamping and R.M. Arrowwood, Jr., Manual for investigation and correction of boiler tube failures, Report CS 3945, Electric Power Research Institute, Palo Alto, CA, April (1985)

6. J. Stringer, "High temperature corrosion problems in the Electric Power Industry and their Solutions" In high temperature corrosion NACE-6, (1983), p.389- 397.

7. S. R. Paterson and T. W. Retig, Remaining life estimation of boiler pressure parts-2.25 Cr-l Mo superheater and Reheater tubes, Project rp-2253-5 final report, Electrical Power Research Institute, Palo Alto, CA (1987). 
